\title{
Women's Empowerment to Improve Nutritional Status in Children: A Systematic Review
}

\author{
Apriyani Puji Hastuti ${ }^{1,2}$, Tintin Sukartini $^{3 *}$, Yuni Sufyanti Arief ${ }^{3}$, Nursalam Nursalam $^{3}$, Hanim Mufarokhah $^{2}$ \\ ${ }^{1}$ Doctoral Nursing Program, Faculty of Nursing, Universitas Airlangga, Surabaya, Indonesia; ${ }^{2}$ Department of Nursing, Institute \\ Technology, Science and Health, RS Dr. Soepraoen, Malang, Indonesia; ${ }^{3}$ Department of Advanced Nursing, Faculty of Nursing, \\ Universitas Airlangga, Surabaya, Indonesia
}

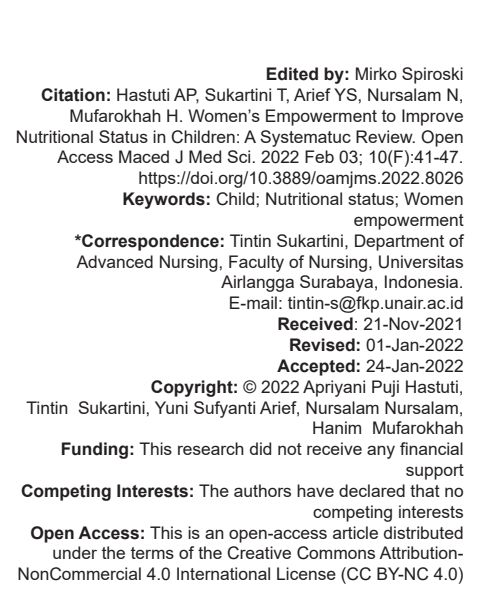

\section{Introduction}

Overnutrition (overweight and obesity) and undernutrition are two types of malnutrition (stunting and wasting). According to "The Conceptual Framework of the Determinants of Child Undernutrition," insufficient nutritional intake and poor child health are the direct causes of nutritional issues in children, including stunting. Stunting can be prevented by solving the causes of nutritional problems, such as food insecurity and limited access to nutritious food (food). The social environment of the child such as feeding practices (caregiving), access to health services, and environmental health, which includes the availability of clean water and sanitation (environmental) facilities also causes nutritional problems in the child. These four variables have an impact on mothers' and children's dietary intake and health. Nutritional issues, including both undernutrition and overnutrition, could be avoided if these four elements are addressed. In addition, environmental and hereditary variables have an impact on children's development, according to research by Dubois et al. (2012), just a little proportion of genetics (4-7\% in women) influences a person's birth height. Environmental factors, on the other hand, have a significant impact on birth (74$87 \%$ in women). This demonstrates that children's growth and development can be aided by favorable environmental factors, depending on their age.

Stunting is addressed with two types of interventions: specialized nutrition interventions for direct causes and sensitive nutrition interventions for indirect reasons. Nutrition-sensitive programs target the root causes of malnutrition (poverty, food insecurity, education, women's empowerment, and social status are all factors to consider) [1], [2]. An integrated 
nutrition intervention improved the complementary feeding practices of children aged 6-9 months who received breast milk and complementary feeding. The nutrition-specific intervention included breastfeeding and complementary feeding advice for mothers, local feeding habits, growth tracking, supplementary nutrition, Vitamin A supplementation, screening, management, and referral for malnutrition. The effect of a combined diet and immunization program on underweight children aged two implies that the combined program was protective. The nutrition-specific intervention included Vitamin A supplementation, exclusive breastfeeding, newborn and young child feeding practices, and growth monitoring [1].

The nutritional quality of food has a significant impact on family health and well-being, particularly for children who need to grow, develop, and achieve their full physical and mental potential [3], [4]. IYCF stands for infant and young child feeding, and it is a critical component of improving child survival and encouraging healthy growth and development. Improved child nutrition has been shown to prevent children from a variety of childhood illnesses.

Several studies suggest that the relationship between women's empowerment and baby nutrition varies by area and participant age [4], [5], [6]. Women's empowerment triumphed over child nutrition and household stability. It had a greater marginal effect on lowering child malnutrition than other variables, according to the study. Women's participation in income-generating activities benefits the household's economic and social status, as well as children's nutritional status and gender disparity. To eliminate gender disparities in health, nutrition, education, and employment-generating activities, a mother's education is critical for a healthy child. The goal of this study is to review the evidence linking women's empowerment and child nutrition. Future research should carefully select women's empowerment indicators in context-specific contexts and use a longitudinal study design to conduct pathway and lifecycle analysis in appropriate populations to clarify the correlation between child nutrition and women's empowerment.

\section{Methods}

As shown in supplementary Table 1, this investigation followed the Preferred Reporting Items for Systematic Review and Meta-Analysis Protocols (PRISMA-P) 2015 checklist.

\section{Data sources and searches}

The database searched from Science Direct, PubMed, Research Gate, and Google Scholar provide studies related to identifying women empowerment to nutritional status in children, determined from 2016 to 2021. In addition, we checked the reference lists of all included articles and conducted a systematic evaluation of the literature.

\section{Study selection}

An inclusion criterion was used to select the studies. Selected inclusion criteria were open access, cross-sectional, pre-experiment, experiment and randomized control trial, qualitative study with mother as a respondent, full-text articles, using English language, and study protocols. We included quantitative and qualitative papers that described intervention efforts. We considered studies that reported on women's empowerment to improve nutritional status as an outcome.

\section{Data collection and analysis}

To find potentially eligible studies, two writers independently examined the titles and abstracts of the obtained records.

\section{Data extraction}

All citations were imported into the Mendeley Desktop Program from an electronic database. To select potentially suitable research, reviewers independently assessed the titles and abstracts of each study found through a literature search. For additional investigation, the complete text of the remaining studies was collected. In this article, the authors carry out a systematic review of relevant data using the keywords "women empowerment," "nutritional status," "child." The first author's name, year of publication, sample size, study design, trial duration, and general characteristics of participants were all collected separately by the same two reviewers.

\section{Results}

\section{Study size}

We conducted identification of 1025 studies in database sources. Seven duplicate studies were excluded continued by 538 studies due to nonparticipants, irrelevant studies, and study protocols. The six remaining studies are included in the current literature review (Figure 1). 


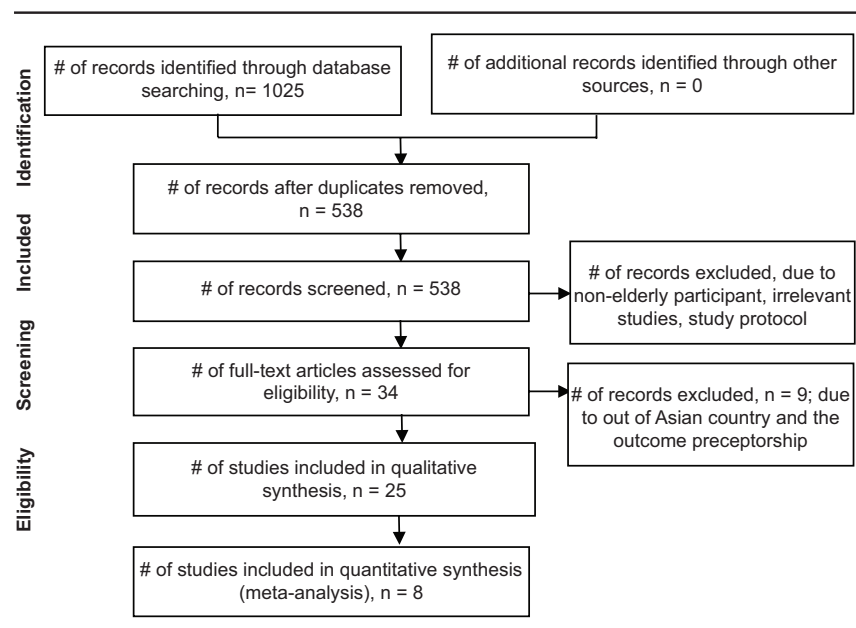

Figure 1: Preferred reporting items for systematic reviews and metaanalysis flowchart

\section{Study characteristics}

Data were extracted from each study that needed the requirements. The extracted data included the characteristics of the study, characteristics of an age-friendly health system, characteristics of the results and, a summary of results.

The standard protocol for selecting studies is suggested in the systematic review method guide, PRISMA. The steps taken are:

\section{Removal of duplication}

1. Examination independently of titles, abstracts, and keywords and delete citations that were not relevant according to the inclusion criteria

2. If the title and abstract likely be following the inclusion criteria and the objectives of the a systematic review, the next step was the selection of journals with full text

3. The final step was the selection of articles.

\section{Results and Discussion}

Promoting women's self-esteem, ability to make their own decisions, and the right to impact societal change for themselves and others are defined as women's empowerment. Accessing household resources, allocating household resources, material allocation, allocating resources within the home childcare system, allocating resources within parent care, and reproductive decisions are all indicators of women empowerment. Empowerment comes in a variety of forms [9].

1. Access to resources Women's asset ownership, women's proportion of income, and women's engagement in groups are all issues to examine 2. Agency Mobility decision, the decision to visit relatives, the decision to allocate food, the decision to allocate money, the decision to allocate child care, the decision to allocate own health care, the decision to allocate family planning

3. completion Social support, women's mobility, credit access, media access, a mother's ability to spend money as she sees fit, feeling power, life satisfaction, and her children's nutritional well-being are all elements to consider.

Women's empowerment is measured using the agricultural index, the regulating behavior index, and the maternal capacities index. The health, nutrition, and socioeconomic status of women, as well as the health of their children, are all affected by their status and empowerment. To build a country or regional aggregate index on women's empowerment, individuallevel statistics on men and women living in the same family are used. The WEAl is a weighted average of two sub-indices: the Gender Parity Index's five aspects of women's empowerment and gender parity, and the Women's Empowerment and Gender Parity Index's five dimensions of gender parity. Women's empowerment encompasses decision-making authority over production, access to and decision-making power over productive resources, control over how money is spent, community leadership, and time management. Empowerment refers to a person's ability to succeed within an area.

According to feminist philosophy, resources and achievement are indirect indicators of women's empowerment, whereas decision-making is a direct measure of women's empowerment. Decision-making, autonomy, and agency are all indicators of women's empowerment. Indicators such as decisions on a woman's healthcare, major household purchases, visits to the woman's family or relatives, and income-control decisions are used to assess women's participation in decision-making.

Asset ownership, which encompasses indicators such as women's home and land ownership, title deed ownership, and land ownership, is the second most widely used domain in women's empowerment. Domestic abuse manifests itself in ways such as the husband burning meals, arguing with him, going out without telling him, ignoring the children, and refusing to have sex with him. Permission to go to the market, permission to go to the health center or traditional doctors, and permission to visit friends are all examples of women's freedom indicators. Forceful actions and demonstrating a sense of self-worth are two aspects of leadership. It also entails being a part of a group and speaking in front of an audience.

Empowering women has a positive impact on children. The mother's nutritional status (Body mass index [BMI], height, weight, and MUAC). The relationship between maternal MUAC and food insecurity was investigated using the mothers' BMI. Food security was 


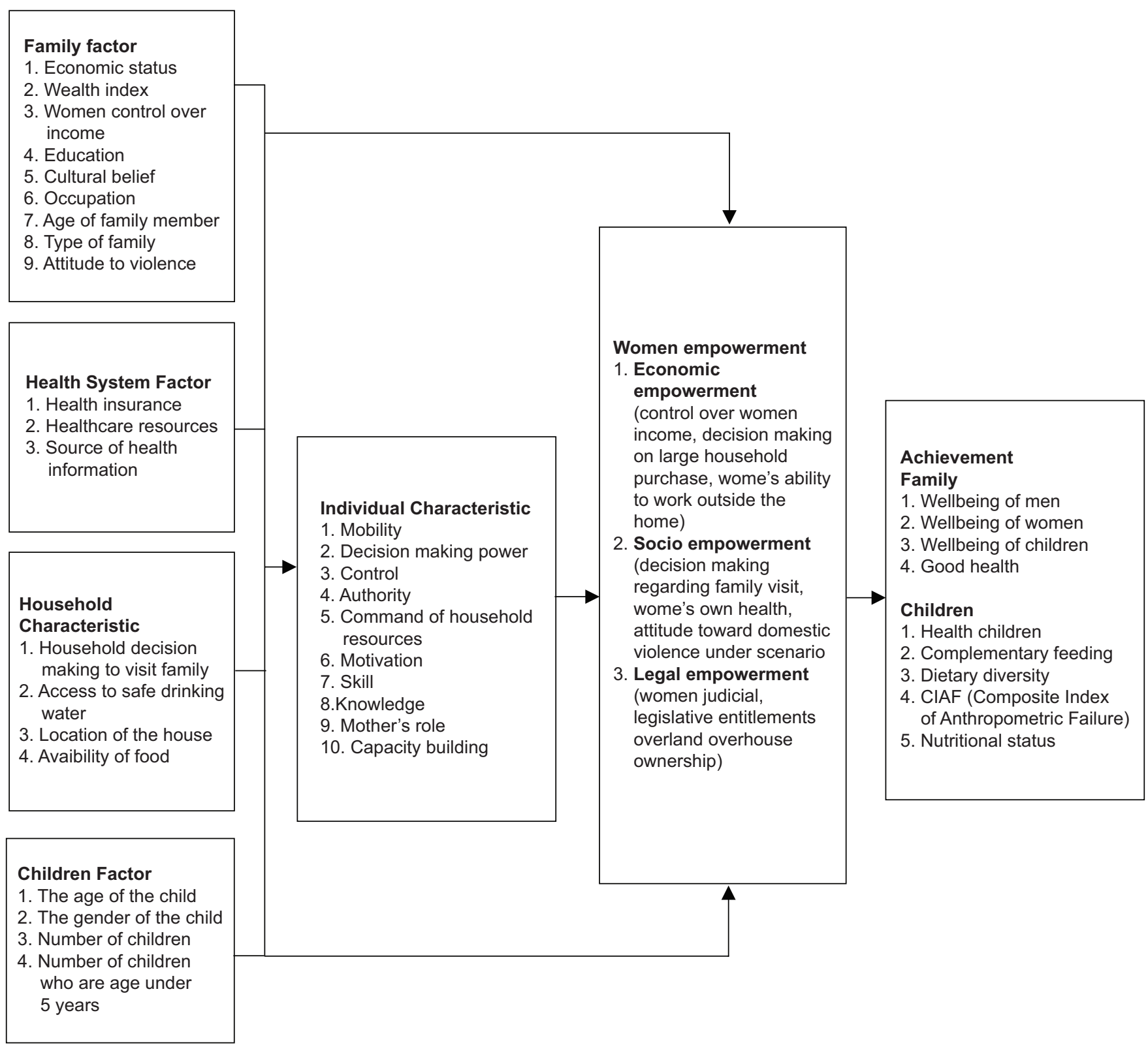

Figure 2: Correlation between women empowerment and nutritional status

found to be strongly associated with maternal MUAC. Other factors that were linked to the moms' MUAC included food variety and the number of meals they ate per day. Undernutrition among mothers was reduced as a result of interventions in maternal health and nutrition, as well as other kinds of women empowerment. In households where mothers lacked authority (decisionmaking processes), this women empowerment helped to reduce female undernutrition [6].

Overpopulation, poverty, a lack of education and information among mothers, gender inequality, food scarcity (poor), breastfeeding, and parenting are all factors that affect children's food security [10].

The majority of studies employ children's anthropometric markers (height-for-age, weightfor-height, and weight-for-age) to determine health outcomes, neonatal mortality, diarrhea therapy, and vaccine use.
The study explains family factors, health system factors, household characteristics, children's factors, and individual characteristics as internal factors for women with women empowerment (Figure 2). the problems that arise in the guidance process of women empowerment especially in the role of mother as a care feeding in children. Furthermore, a study by Jones examined women's empowerment indicator social/ human asset intrinsic, intrinsic agency/attitudes about intimate partner violence, and instrumental agency (influence in household decision making) to child nutritional status.

Our reviews find evidence that women's empowerment in the household is generally associated with child nutritional well- being and it is correctional direct with child age, household wealth, well- being and focus on women's autonomy, control, and decisionmaking power [8], [10]. Mobility autonomy and financial 


\section{Table 1: Summary or the Review Studies}

\begin{tabular}{|c|c|c|c|}
\hline $\begin{array}{l}\text { Authors and } \\
\text { years }\end{array}$ & $\begin{array}{l}\text { Study design, sample, variable, instrument, } \\
\text { analysis }\end{array}$ & The outcome of analysis factors & Summary of result \\
\hline [1] & $\begin{array}{l}\text { Design: a correlation study } \\
\text { Sample: } 11716 \text { women } \\
\text { Variable: women's empowerment } \\
\text { Instrument: freedom of mobility index, household }\end{array}$ & $\begin{array}{l}\text { Financial autonomy, home autonomy, } \\
\text { freedom mobility, and attitude toward } \\
\text { domestic violence are all examples of } \\
\text { women's empowerment }\end{array}$ & $\begin{array}{l}\text { Child malnutrition was linked to an increase in } \\
\text { household size in a positive significant correlation } \\
\text { and substantial way }\end{array}$ \\
\hline
\end{tabular}

Analysis: logistic regression

Instrument: freedom of mobility index, household autonomy index, attitude toward domestic violence index, The composite index of anthropometric failure (CIAF)

[2] Design: a correlation study Design: a correlation study
Sample: 640 mother-child Variable: women empowerment (economies, socio- familial and legal) and sociodemographic (decision large household purchase, decision family visit, ownership of land, age of child and mother educational level), minimum daily meal frequency Instrument:

Analysis: univariate and multiple linear regression design Variable: sociodemographic (household head, marital status, family size, educational level, occupation, female authority, household monthly income, household food security/insecurity, and food/diet diversity), anthropometric data (BMI, MUAC)

Instrumen: Household food insecurity access scale

Analysis: binary logistic regression Kenya, Rwanda, Tanzania, and Uganda (n $1 / 4$ 13,780) Variable: women empowerment and Child nutrition

Instrument: maternal BMI and stratification by wealth index Analysis: Spearman's rho correlation Sample: In the cluster-randomized controlled trial, villages were randomly assigned to a control arm $(n=25)$ or one of two treatment arms, which differed in who implemented the BCC strategyeither older women leaders $(n=15)$ or health committee members $(n=15)$

Variable: women's empowerment, nutrition outcome

Intervention: The E-HFP program, Instrument: anthropometry (measured by trained anthropometers), child $\mathrm{Hb}$ (blood collected by fingerpick), and women's empowerment (measured by Women's Empowerment in Agriculture Index) Analysis: multivariate logistic regression

women's empowerment, three latent domains: social/human assets ("assets") intrinsic agency (attitudes about intimate partner violence), and instrumental agency (influence in household decision making)

Domain: Human and Social

Assets (Assets) -> Age at first sex, age at first cohabitation, Age at first birth. Domain Intrinsic Agency ->Goes out without spouse, if neglects child, If argues with husband, If refuses sex, If burns food. Domain: Instrumental Agency For respondent's earnings

For respondent's health

For large purchases for family/friend's visits Mediator: Women's BMI. Outcomes: Child Nutritional Status: Height-for-age z-Score, Weight-for-age z-Score, Anemia status

Purchasing decisions, healthcare decisions family planning decisions, and spousal communication are all examples of women's empowerment

Result of nutrition: wasting and hemoglobin
Data from decisions on large household purchases $(\beta$ $=0.351, P<0.01$ ) family visits $(\beta=0.743, P<0.01)$, home ownership $(\beta=-0.245, P<0.10)$, age of child $(\beta=1.387, P<0.01)$, mother's educational attainment $(\beta=0.496, P<0.10)$ and place of residence $(\beta=-0.298, P<0.10)$ showed significant positive association with minimum daily meal frequency in Ghana

From the total participants, $12.6 \%(95 \% \mathrm{Cl}$ $11.6-13.6 \%$ ) had a BMI, $18.5 \mathrm{~kg} / \mathrm{m}^{2}$. Comparison of maternal undernutrition in the two study areas revealed $8.8 \%(95 \% \mathrm{Cl} 7.6-10.2 \%)$ in the program area and $16.4 \%(95 \% \mathrm{Cl} 14.8-18.1 \%)$ in nonprogram areas were undernourished. Severe food insecurity was significantly associated with BMI of mothers (AORs 3.6 and $2.31,95 \% \mathrm{Cl}$ 2.32-5.57 and 1.52-3.5, respectively) in both program and nonprogram areas. Mild (AOR 1.77, $95 \% \mathrm{Cl} 1.21-2.6$ ) and moderate (AOR 1.6, 95\% C $1.18-2.16$ ) food insecurity significantly associated with maternal undernutrition in nonprogram areas. In the same way, all forms of food insecurity were significantly associated with a maternal middle upper-arm circumference in both program and nonprogram areas. The odds of mothers who did not exercise decision-making practice on the household income was also 4.13 times higher than those who did (AOR 4.13, 95\% Cl 2.2-7.77) in the program area

Assets were indirectly associated with child $\mathrm{HAZ}$ and $\mathrm{WHZ}$ through intrinsic agency and maternal BMI. In the lowest wealth category, the direct effects from women's empowerment to child nutritional status were significant (assets and instrumental agency were associated with anemia; intrinsic agency associated with HAZ). In the highest wealth category, direct effects from women's empowermen on child nutritional status were significant (intrinsic and instrumental agency associated with $\mathrm{WHZ}$. Improving women's empowerment, especially intrinsic agency, in East Africa could improve child nutrition directly and via improved maternal nutrition

Improvements in women's empowerment in the categories of spousal communication, purchasing decisions, healthcare decisions, and family planning decisions were linked to the program's influence on reducing waste, with spousal communication accounting for the largest amount. The increase in hemoglobin was unrelated to improvements in women's empowermen 
Table 1: (Continued)

\begin{tabular}{|c|c|c|c|}
\hline $\begin{array}{l}\text { Authors and } \\
\text { years }\end{array}$ & $\begin{array}{l}\text { Study design, sample, variable, instrument, } \\
\text { analysis }\end{array}$ & The outcome of analysis factors & Summary of result \\
\hline [6] & $\begin{array}{l}\text { Design: a survey study } \\
\text { Sample: 10,879 samples, various years 2011- } \\
2016 \text { in Bangladesh, Nepal, Cambodia, Ghana, } \\
\text { Mozambique, Tanzania } \\
\text { Variable: Woman empowerment, Women's } \\
\text { nutrition outcomes, and Children's outcomes } \\
\text { Instrument: anthropometry (as determined } \\
\text { by trained anthropometers) and female } \\
\text { empowerment (as determined by the Women's } \\
\text { Empowerment in Agriculture Index) } \\
\text { Analysis: multivariate logistic regression }\end{array}$ & $\begin{array}{l}\text { The 5DE measures women's empowerment } \\
\text { across five domains: } \\
\text { 1. Agricultural production decisions (input } \\
\text { in productive decisions, autonomy in } \\
\text { production) } \\
\text { 2. Control over productive resources } \\
\text { and the ability to make judgments } \\
\text { regarding them (ownership of assets, } \\
\text { purchase-sale-or-transfer of assets, } \\
\text { access to and decisions about credit) } \\
\text { 3. Financial management (financial } \\
\text { management) } \\
\text { 4. Leadership responsibilities in the } \\
\text { community (group member, public } \\
\text { speaking), and } \\
\text { 5.Time management (workload, leisure) } \\
\text { Women's dietary variety score and BMI } \\
\text { Exclusive breastfeeding, children's dietary } \\
\text { diversity score, HAZ, and WHZ are some of } \\
\text { the children's outcomes }\end{array}$ & $\begin{array}{l}\text { There are rarely meaningful links between overall } \\
\text { empowerment scores and nutritional results. Only } \\
\text { child HAZ is positively associated with women's } \\
\text { empowerment, but reduced intrahousehold } \\
\text { inequality is linked to a higher likelihood of exclusive } \\
\text { breastfeeding and higher HAZ but lowers BMI. The } \\
\text { subdomain indicators, on the other hand, show more } \\
\text { substantial relationships, implying that different levels } \\
\text { of empowerment have costs }\end{array}$ \\
\hline [7] & $\begin{array}{l}\text { Design: an experimental study } \\
\text { Sample: } 900 \text { households } \\
\text { Variable: Woman empowerment and poverty } \\
\text { Intervention: training, cooperatives, and } \\
\text { micro-credit services. } \\
\text { Instrument: Include GDI, GEM, and WEAI } \\
\text { Analysis: comparative using t-test }\end{array}$ & $\begin{array}{l}\text { Women's empowerment is defined as their } \\
\text { ability to make decisions in six areas at } \\
\text { home: (1) agricultural production, (2) access } \\
\text { to and control over productive resources, (3) } \\
\text { access to and control over household } \\
\text { assets, (4) access to and control over food } \\
\text { and high-frequency non-food items, (5) } \\
\text { access to credit, and (6) social connection in } \\
\text { the community. } \\
\text { Poverty }\end{array}$ & $\begin{array}{l}\text { Women's empowerment has a favorable impact } \\
\text { on poverty reduction, and the women who have } \\
\text { benefited have helped to raise household incomes } \\
\text { and living standards }\end{array}$ \\
\hline [8] & $\begin{array}{l}\text { Design: Quantitative research } \\
\text { Sample: households=373; n women=346; n } \\
\text { children=114 } \\
\text { Variable: women's empowerment-food security, } \\
\text { maternal and child diet diversity } \\
\text { Instrument: Household food insecurity access } \\
\text { scale, WELI, WEAI, WDDS, WEAI, WEAl, WDDS, } \\
\text { HFIAS } \\
\text { Analysis: regression analyses }\end{array}$ & $\begin{array}{l}\text { Woman empowerment: } \\
\text { 1. Control and access to resources: } \\
\text { ownership } \\
\text { 2. Income control and utilization: } \\
\text { 3. Workload and personal time management } \\
\text { 4. Meat, fish, and eggs are all part of a } \\
\text { woman's diet during pregnancy } \\
\text { 5. Child diet diversity refers to how much } \\
\text { meat, fish, or eggs a child consumes } \\
\text { 6. Maternal diet diversity: Woman's } \\
\text { consumption of meat, fish, eggs }\end{array}$ & $\begin{array}{l}\text { In the qualitative research, all three empowerment } \\
\text { domains were positively related to food security and } \\
\text { nutrition }\end{array}$ \\
\hline
\end{tabular}

autonomy results suggest with child nutrition. Decisionmaking regarding her children's nutritional status because can gain knowledge and skills and suggest a positive association with child WAZ.

Evidence from a study shows that women's empowerment more strongly of quality of infant and young children feeding practices whereas weekly associated with nutritional status. Contribution of women's ability to access resources such as control over mobility, access to information, agency decisions for better household food security [9]. Allocation of household resources for child nutrition, material resources allocation, women's decision-making about childcare, and child health.

Child growth refers to a measurable change in body size, physics, and composition. A child from birth to 5 years is at risk due to malnutrition and infections where malnutrition may begin during intrauterine until the first 6 months. Children's nutritional status is children $\mathrm{HAZ}, \mathrm{WHZ}$, and WAZ. In the nutrition literature, it is common to use individual dietary scores (DDS) as an indicator of nutrient adequacy and access to a variety of food. Starchy staples, dark green leafy vegetables, other vitamins $A$ rich fruits and vegetables, other fruit and vegetables, organ meat, meat and fish, eggs, legumes, nuts and seeds, milk and milk products were the nine food groups.

\section{Conclusion}

The result of the study showed that indicators of women empowerment such as economic empowerment, socio empowerment, and legal empowerment. On another hand, women's empowerment can be influenced by several factors, family factors (economic status, wealth index, women control over income, education, cultural belief, occupation, age of the family member, type of family, attitude to violence), health system factor (health insurance, healthcare resources, source of health information), household characteristic (household decision making to visit family, access to safe drinking water, location of the house, and availability of food), children factor (the age of the child, gender, number of children) and women ability (mobility, decision making, control, authority, command of household resources, motivation, skill, knowledge, mothers role, and capacity building). Further research should use a longitudinal study design to conduct pathway and lifecycle analysis in appropriate populations to clarify the relationship between women's empowerment and nutritional status in children, as this review aims to review the evidence linking women's empowerment and nutritional status in children. Women's empowerment has the potential to improve achievement in healthy children through 
complementary feeding, dietary diversity so it can enhance nutritional status. While its study suggest a positive trend furthermore movement includes targeting children's nutrition within the first 1000 days and monitoring nutrition indicators.

\section{Recommendation}

However, the research suggests that incorporating nutrition treatments into related programs has a lot of potential for ensuring appropriate women's empowerment, efficient health service delivery, and a positive influence on nutritional status. We suggested that context-specific learning of integrating malnutrition be expanded to include causal modeling and a longitudinal study design be used to conduct pathway and lifecycle analysis in appropriate populations to clarify the relationship between women's empowerment and children's nutritional status.

The method can also be used to track how well the Multi-sectoral Nutrition Plan is integrating nutrition and guiding change.

The impact of women empowerment should be provided to the community husband and other household members so that they encourage women to actively participate in the matter the household pertains.

\section{References}

1. Shafiq A, Hussain A, Asif M, Hwang J, Jameel A, Kanwel S. The effect of "women's empowerment" on child nutritional status in Pakistan. Int J Environ Res Public Health. 2019;16(22):4499. https://doi.org/10.3390/ijerph16224499

PMid:31739650

2. Dadzie LK, Amo-Adjei J, Esia-Donkoh K. Women empowerment and minimum daily meal frequency among infants and young children in Ghana: Analysis of Ghana demographic and health survey. BMC Public Health. 2021;21(1):1700. https://doi. org/10.1186/s12889-021-11753-1

PMid:34535097

3. Motbainor A, Worku A, Kumie A. Household food insecurity is associated with both body mass index and middle upper-arm circumference of mothers in Northwest Ethiopia: A comparative study. Int J Womens Health. 2017;9:379-89.

4. Phinney A, Chesla CA, Taylor K, Blacklock C, Hayward G, Bidwell P, et al. Int Nurs Rev. 2016;20(1):1-10. Available from: https://www.scopus.com/inward/record.uri?eid=2-s2.084896730539\& partnerid $=40 \&$ md5 $=c 7576 d 3851$ bea34af88202 de8b5b3857 [Last accessed on 2009 Jul 14].

5. Alemayehu $M$, Tinsae $F$, Haileslassie $K$, Seid $O$, Gebregziabher G, Yebyo H, et al. Understanding innovation: The development and scaling of orange-fleshed sweetpotato in major African food systems. World Dev. 2021;3(4):42-55. Available from: https://www.sciencedirect.com/science/article/ pii/S0140673615001282. [Last accessed on 2021 May 25].

6. Malapit H, Sraboni E, Quisumbing A, Ahmed AU. Intrahousehold empowerment gaps in agriculture and children's well-being in Bangladesh. Polit Econ Dev Domest Dev Strateg eJ. 2019;37(2):176-203. Available from: https://www.semanticscholar.org/ paper/2c826ae15ca177f5fa9b502b082ce8fb24b6018d

7. Madzorera I, Fawzi W. Women empowerment is central to addressing the double burden of malnutrition. EClinicalMedicine. 2020;20:100286. https://doi.org/10.1016/j.eclinm.2020.100286 PMid:32300740

8. Johari F, Robeyns I, Shafiq A, Hussain A, Asif M, Hwang J, et al. Participatory women's groups and counseling through home visits to improve child growth in rural eastern India: Protocol for a cluster randomized controlled trial. PLoS One. 2015;17(1):1-12.

9. Malapit HJ, Quisumbing AR. What dimensions of women's empowerment in agriculture matter for nutrition in Ghana? Food Policy. 2015;52:54-63.

10. Kabeer N. Resources, agency, achievements: Reflections on the measurement of women's empowerment. Dev Change. 1999;30(3):435-64. 